\title{
Genome-based polymorphic microsatellite development and validation in the mosquito Aedes aegypti and application to
} population genetics in Haiti

\author{
Diane D Lovin ${ }^{\dagger}$, Katie O Washington ${ }^{\dagger}$, Becky deBruyn, Ryan R Hemme, \\ Akio Mori, Sarah R Epstein, Brent W Harker, Thomas G Streit and \\ David W Severson*
}

Address: Eck Institute for Global Health, Department of Biological Sciences, University of Notre Dame, Notre Dame, IN 46556-5645 USA

Email: Diane D Lovin - dlovin@nd.edu; Katie O Washington - kwashin2@nd.edu; Becky deBruyn - bde@nd.edu;

Ryan R Hemme - rhemme@nd.edu; Akio Mori - amori@nd.edu; Sarah R Epstein - epstein.5@nd.edu; Brent W Harker - harker.1@nd.edu; Thomas G Streit - tstreit@nd.edu; David W Severson* - severson.1@nd.edu

* Corresponding author †Equal contributors

Published: 9 December 2009

BMC Genomics 2009, 10:590 doi:10.1186/147|-2164-10-590
Received: 16 July 2009

Accepted: 9 December 2009

This article is available from: http://www.biomedcentral.com//47/-2/64/I0/590

(c) 2009 Lovin et al; licensee BioMed Central Ltd.

This is an Open Access article distributed under the terms of the Creative Commons Attribution License (http://creativecommons.org/licenses/by/2.0), which permits unrestricted use, distribution, and reproduction in any medium, provided the original work is properly cited.

\begin{abstract}
Background: Microsatellite markers have proven useful in genetic studies in many organisms, yet microsatellite-based studies of the dengue and yellow fever vector mosquito Aedes aegypti have been limited by the number of assayable and polymorphic loci available, despite multiple independent efforts to identify them. Here we present strategies for efficient identification and development of useful microsatellites with broad coverage across the Aedes aegypti genome, development of multiplex-ready PCR groups of microsatellite loci, and validation of their utility for population analysis with field collections from Haiti.
\end{abstract}

Results: From 79 putative microsatellite loci representing 31 motifs identified in 42 whole genome sequence supercontig assemblies in the Aedes aegypti genome, 33 microsatellites providing genomewide coverage amplified as single copy sequences in four lab strains, with a range of 2-6 alleles per locus. The tri-nucleotide motifs represented the majority $(5 \mathrm{I} \%)$ of the polymorphic single copy loci, and none of these was located within a putative open reading frame. Seven groups of 4-5 microsatellite loci each were developed for multiplex-ready PCR. Four multiplex-ready groups were used to investigate population genetics of Aedes aegypti populations sampled in Haiti. Of the 23 loci represented in these groups, 20 were polymorphic with a range of 3-24 alleles per locus (mean $=8.75$ ). Allelic polymorphic information content varied from $0.17 \mathrm{I}$ to 0.867 (mean $=0.545)$. Most loci met Hardy-Weinberg expectations across populations and pairwise $\mathrm{F}_{\mathrm{ST}}$ comparisons identified significant genetic differentiation between some populations. No evidence for genetic isolation by distance was observed.

Conclusion: Despite limited success in previous reports, we demonstrate that the Aedes aegypti genome is well-populated with single copy, polymorphic microsatellite loci that can be uncovered using the strategy developed here for rapid and efficient screening of genome supercontig assemblies. These loci are suitable for genetic and population studies using multiplex-PCR. 


\section{Background}

The mosquito, Aedes aegypti, is the principal global vector for the yellow fever and dengue viruses, and also one of the best genetically characterized insects [1]. Of African origin, Ae. aegypti has successfully colonized most subtropical and tropical regions of the world, largely as a consequence of human activities. This mosquito has been and remains the most commonly studied mosquito species, particularly for genetic analyses of disease vector/pathogen interactions because it breeds in small water-holding containers, its eggs are resistant to desiccation and persist in a pre-embryonated state, and it readily adapts to laboratory culture. Detailed genetic studies have emerged from linkage maps for Ae. aegypti generated from isozyme and mutant marker loci [2], RAPDs [3], RFLPs [4,5], and SSCPs [6]. Demonstration that RFLP markers based on cDNAs had inter-specific utility [7] facilitated development of comparative linkage maps for several mosquito species [8-12].

Microsatellites are simple sequence repeats of tandem 1-6 base motifs that are frequently distributed throughout eukaryote genomes. Because repeat number at individual loci can vary among individuals and polymorphisms can efficiently be uncovered using PCR, microsatellites have become powerful tools for genetic studies in many organisms [13-15]. Of interest, useful microsatellite loci in some organisms including Ae. aegypti are not abundant or are recalcitrant to common methods of identification. In Ae. aegypti, these include microsatellite enriched genomic library construction and screening [16-18], examinations of expressed gene coding sequences $[19,20]$, and oligonucleotide-based screening of select cosmid genomic clones [18]. Disappointingly, the combined efforts of these studies resulted in only 20 useful microsatellite marker loci, several of which showed reduced polymorphism. These results were most likely due to their close association with repetitive elements as opposed to microsatellite frequency in the Ae. aegypti genome [18]. Availability of a partial Ae. aegypti genome sequence in 2005 provided the opportunity to perform genome scans for microsatellites and, indeed, an additional 13 polymorphic microsatellites were uncovered [21].

Here we present a systematic approach to efficient polymorphic microsatellite marker development in Ae. aegypti based on intensive scans of supercontig assemblies from the whole genome shotgun sequence (wgs) assembly for Ae. aegypti [22]. In addition, we identified multiplex combinations of microsatellite loci that facilitate rapid genome-wide genotyping and demonstrate the utility of these microsatellite loci in a preliminary investigation of Ae. aegypti population genetic structure in Haiti.

\section{Results and Discussion}

\section{Microsatellite identification, assays and utility}

Tandem Repeats Finder (TRF) [23] was used to systematically screen 42 wgs supercontig sequence assemblies in the Ae. aegypti genome for polymorphic single copy microsatellites (Figure 1). The supercontigs were selected on the basis of containing previously characterized genetic marker loci distributed across all three Ae. aegypti chromosomes [5]. Of 75 putative microsatellite loci tested, we determined that 44 amplified as single copy sequences in all or some of the four mosquito lab strains tested, of which 33 were found to be polymorphic across the four strains with a range of 2-6 alleles per locus (Additional File 1). These included 18 loci on chromosome 1, 5 loci on chromosome 2 , and 10 loci on chromosome 3 . Of the remaining 31 putative loci, 28 were determined to represent multicopy sequences and four sequences failed to amplify. In addition, four supercontigs contained no useful microsatellites based on our selection criteria. Chromosome locations for supercontigs and associated microsatellites were assigned based on the linkage map positions of the previously defined genetic loci. An additional 28 putative microsatellite loci amplified as multiple copies. No microsatellite sequences were evident in four supercontigs. Thus, direct scans of Ae. aegypti supercontigs provided a rapid and efficient mechanism for developing useful microsatellite loci and also the opportunity to leverage existing information on supercontig genome positions relative to the existing genetic linkage map. When coupled with the previously described 33 microsatellite loci $[16,18-21]$, this effort has doubled the number of available polymorphic loci.

We tested microsatellites representing 31 motifs (1-6 bp); these included one single nucleotide ( $\mathrm{n}=3$ sequences), five di-nucleotide $(n=27), 18$ tri-nucleotide $(n=35)$, six tetra-nucleotide $(n=9)$, and one hexa-nucleotide $(n=1)$ motifs (Table 1). The single-copy polymorphic microsatellites comprise 22 independent motifs, of which 13 were tri-nucleotide motifs and these represented the majority (18 of 33) of the polymorphic single copy loci. Of particular note, $51 \%$ (18 of 35) of the tri-nucleotide and $67 \%$ ( 6 of 9 ) of the tetra-nucleotide microsatellites were polymorphic single copy loci, while only 33\% (9 of 27) of the di-nucleotide microsatellites were polymorphic single copy loci. Although a small number of polymorphic trinucleotide microsatellite loci contained within coding regions have been identified in previous studies [20], BLAST analyses against the annotated Ae. aegypti genome assembly at VectorBase [24] indicated that none of our polymorphic tri-nucleotide microsatellites were within putative coding regions. 
BLAST a target sequence at VectorBase to find its location in a supercontig
Run the Tandem Repeats Finder program on the supercontig sequence to identify microsatellites

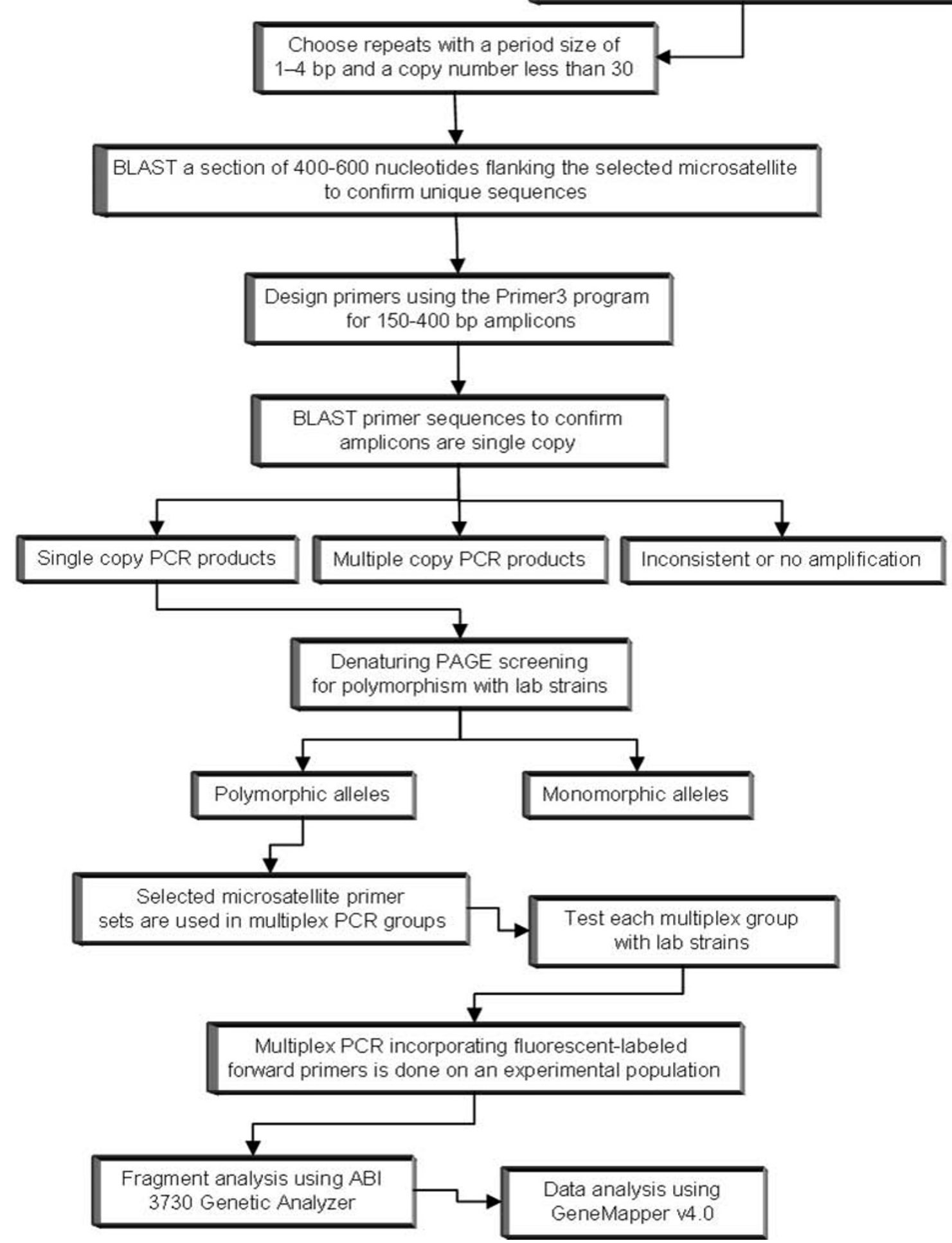

Figure I

Approach to genome-based microsatellite identification, validation, and analysis in Aedes aegypti. 
Table I: Microsatellite loci PCR screen results categorized by repeat motif.

\begin{tabular}{|c|c|c|c|c|c|}
\hline Repeat & $\begin{array}{l}\text { Polymorphic } \\
(n=33)\end{array}$ & $\begin{array}{l}\text { Monomorphic } \\
(n=3)\end{array}$ & $\begin{array}{l}\text { Strain-specific } \\
\text { amplification } \\
(n=8)\end{array}$ & $\begin{array}{l}\text { Multiple copies } \\
\quad(n=28)\end{array}$ & $\begin{array}{c}\text { No amplification } \\
(n=3)\end{array}$ \\
\hline \multicolumn{6}{|l|}{$\begin{array}{l}\text { Single nucleotide } \\
\text { repeats }\end{array}$} \\
\hline $\mathrm{A} / \mathrm{T}$ & & & 2 & 1 & \\
\hline \multicolumn{6}{|l|}{$\begin{array}{l}\text { Dinucleotide } \\
\text { repeats }\end{array}$} \\
\hline $\mathrm{AG} / \mathrm{TC}$ & 1 & & & 2 & \\
\hline AT/TA & 2 & I & I & 9 & 1 \\
\hline CA/GT & $\mathrm{I}$ & & I & I & 1 \\
\hline CT/GA & 4 & & & 1 & \\
\hline TG/AC & 1 & & & & \\
\hline \multicolumn{6}{|l|}{$\begin{array}{l}\text { Trinucleotide } \\
\text { repeats }\end{array}$} \\
\hline AAC/TTG & I & & & & \\
\hline AAG/TTC & $\mathrm{I}$ & & & 2 & \\
\hline AAT/TTA & 2 & & & & \\
\hline ACG/TGC & 2 & & & & \\
\hline ATA/TAT & 1 & & & & \\
\hline ATC/TAG & & & & 2 & 1 \\
\hline ATG/TAC & 1 & & & & \\
\hline ATT/TAA & 1 & & I & & \\
\hline CAA/GTT & & & I & & \\
\hline CAG/GTC & & & & I & \\
\hline CAT/GTA & 1 & & & 1 & \\
\hline CCA/GGT & & 1 & & & \\
\hline CGA/GCT & $\mathrm{I}$ & & I & I & \\
\hline CGT/GCA & 2 & & & & \\
\hline CTA/GAT & & I & & 2 & \\
\hline CTT/GAA & 3 & & & I & \\
\hline GAC/CTG & 1 & & & 1 & \\
\hline TGA/ACT & 1 & & & & \\
\hline \multicolumn{6}{|l|}{$\begin{array}{l}\text { Four or more } \\
\text { nucleotide repeats }\end{array}$} \\
\hline AATA/TTAT & & & I & I & \\
\hline ATCC/TAGG & 1 & & & & \\
\hline ATGG/TACC & 1 & & & & \\
\hline ATTT/TAAA & 3 & & & & \\
\hline TGTA/ACAT & $\mathrm{I}$ & & & & \\
\hline TTTA/AAAT & & & & 1 & \\
\hline TGGACT/ACCTGA & & & & I & \\
\hline
\end{tabular}

To improve the utility and efficiency of microsatellites for genotyping applications in Ae. aegypti, we developed seven groups of 4-5 loci each for multiplex-ready PCR [25] (Table 2). Individual loci in each group were selected to provide broad genome representation and relatively uniform amplification under the same PCR conditions when multiplexed. PCR groups $1 \mathrm{~A}$ and $4 \mathrm{~A}$ represent slight variants on groups 1 and 4, respectively: most of the loci are common among the respective groups with some interchange of microsatellite loci that provide for potential diversity of chromosome coverage but still amplify well as multiplex PCR groups. Primers were designed to generate amplicons from $\sim 150-400$ bp and were fluorescently labeled for analysis by capillary electrophoresis. We included four microsatellite loci described elsewhere $[18,21]$ in some of the groups. However, in conjunction with optimizing amplicon sizes for multiplex-ready PCR, we designed at least one new primer for each of these loci (Additional File 2).

\section{Genetic patterns of Aedes aegypti populations in Haiti}

We used multiplex-ready PCR groups 1, 1B, 2, 3A and 4 to conduct investigations of seven $A e$. aegypti populations sampled in Haiti during June 2008. PCR groups $1 \mathrm{~A}$ and 
Table 2: Multiplex-ready PCR groups.

\begin{tabular}{|c|c|c|c|c|}
\hline Group & Map location ${ }^{a}$ & Microsatellite Locus & Amplicon size (bp) & Fluorochrome \\
\hline \multirow[t]{4}{*}{$\mathbf{I}$} & $2-70.2$ & II32CTI & $17 \mid$ & 6-FAM ${ }^{\circledR}$ \\
\hline & $3-00.0$ & $30 I C T I$ & 267 & NED ${ }^{\circledR}$ \\
\hline & $\mathrm{I}-65.5$ & 440TGTAI & 294 & 6-FAM \\
\hline & $2-29.4$ & $462 \mathrm{GA} I^{\mathrm{b}}$ & 343 & $\mathrm{HEX}^{\circledR}$ \\
\hline \multirow[t]{4}{*}{ IA } & $2-70.2$ & II32CTI & $17 \mid$ & 6-FAM \\
\hline & $3-50.0$ & 2 I7CTTI & 257 & NED \\
\hline & $2-29.4$ & $462 \mathrm{GA} I^{\mathrm{b}}$ & 343 & HEX \\
\hline & $\mathrm{I}-56.4$ & $68 \mathrm{GACl}$ & 386 & 6-FAM \\
\hline \multirow[t]{4}{*}{ IB } & $2-70.2$ & II32CTI & $|7|$ & 6-FAM \\
\hline & $\mathrm{I}-29.7$ & 7IATI & 191 & NED \\
\hline & $3-64.2$ & $470 \mathrm{CT} 2$ & 315 & 6-FAM \\
\hline & $2-29.4$ & $462 \mathrm{GA} I^{\mathrm{b}}$ & 343 & HEX \\
\hline \multirow[t]{5}{*}{2} & $2-07.3$ & 328CTTI & 229 & 6-FAM \\
\hline & $3-64.2$ & 470AGI & 252 & HEX \\
\hline & $3-23.5$ & 766ATTI & 301 & NED \\
\hline & $2-36.7$ & I09CTIc & 355 & 6-FAM \\
\hline & $\mathrm{I}-29.7$ & 7ICGTI & 387 & HEX \\
\hline \multirow[t]{5}{*}{ 3A } & $1-10.2$ & I76TGI & 166 & HEX \\
\hline & $3-32.1$ & 69TGAI & 214 & NED \\
\hline & $1-19.6$ & |2ATGI & 231 & 6-FAM \\
\hline & $3-14.6$ & 288CTAI & 321 & 6-FAM \\
\hline & $2-00.0$ & I45TAAA| & 335 & HEX \\
\hline \multirow[t]{5}{*}{4} & $1-19.6$ & I2ACGI & 177 & 6-FAM \\
\hline & $2-29.4$ & 88ATIc & 221 & HEX \\
\hline & $3-43.7$ & $86 \mathrm{AClc}$ & 257 & NED \\
\hline & $3-00.0$ & $301 \mathrm{ACGI}$ & 287 & 6-FAM \\
\hline & $3-57.1$ & 20IAATI & 336 & HEX \\
\hline \multirow[t]{5}{*}{ 4A } & $1-19.6$ & I2ACGI & 177 & 6-FAM \\
\hline & $2-47.9$ & 25AAGI & 214 & HEX \\
\hline & $3-43.7$ & $86 \mathrm{ACl}$ & 257 & NED \\
\hline & $3-00.0$ & $30|A C G|$ & 287 & 6-FAM \\
\hline & $3-57.1$ & 20IAATI & 336 & HEX \\
\hline
\end{tabular}

aGenetic map position after Severson et al. [5]

bAdapted from Chambers et al. [18] (Additional File 2)

cAdapted from Slotman et al. [2I] (Additional File 2)

4A as variants on groups 1 and 4, respectively, were not included in our assays of samples from Haiti. Of the 23 microsatellite loci represented in these groups, 20 were polymorphic with a range of 3 to 24 alleles per locus with a mean of 8.75 alleles per locus among a total of 277 individuals across the seven sample sites (Table 3 ). Further, for 17 of the 20 polymorphic loci, at least 5 alleles were segregating among the populations. Allelic polymorphic information content (PIC) varied from 0.171 to 0.867 across loci with a mean PIC $=0.545$ (Additional File 3), indicating that a large proportion of these loci are highly informative for population studies. Thus, these multiplexready PCR groups represent an efficient option for rapidly screening individual mosquitoes in 96-well microplate format. Our genotype analyses of mosquito collections from Haiti with the selected multiplex-ready PCR groups indicated that these microsatellite loci exhibited higher levels of polymorphism compared with previous microsatellite data reported for Ae. aegypti field populations in Côte d'Ivoire, Kenya and Vietnam, respectively $[19,21,26]$.

The observed heterozygosity was generally high among all loci and across the seven populations, with notable exceptions at three loci (Additional File 3). The 301CT1, 328CTT1, and 145TAAA1 loci each showed very low, and in several populations, no heterozygosity. While we have no explanation for this phenomenon, it is interesting to 
Table 3: Unique alleles in a Haiti population $(n=277$ progeny).

\begin{tabular}{|c|c|c|c|}
\hline Multiplex group & SSR Locus & \# of alleles & Size range (bp) \\
\hline \multirow[t]{3}{*}{$\mathbf{I}$} & II32CTI & 24 & $151-203$ \\
\hline & $30 I C T I$ & 11 & $262-282$ \\
\hline & 462GAI & 13 & $331-359$ \\
\hline \multirow[t]{2}{*}{ IB } & 7IATI & 3 & $186-190$ \\
\hline & $470 \mathrm{CT} 2$ & 6 & $312-322$ \\
\hline \multirow[t]{5}{*}{2} & $328 \mathrm{CTTI}$ & 7 & $213-233$ \\
\hline & 470AGI & 8 & $227-255$ \\
\hline & 766ATTI & 5 & $300-320$ \\
\hline & I09CTI & 14 & $332-358$ \\
\hline & 7ICGTI & 5 & $380-392$ \\
\hline \multirow[t]{5}{*}{ 3A } & |76TG| & 15 & $136-172$ \\
\hline & 69TGAI & 4 & $212-218$ \\
\hline & |2ATGI & 7 & $205-233$ \\
\hline & 288CTAI & 3 & 3||$-32 \mid$ \\
\hline & I45TAAA| & 11 & $318-350$ \\
\hline \multirow[t]{5}{*}{4} & I2ACG I & 6 & $167-179$ \\
\hline & 88ATI & 14 & $219-248$ \\
\hline & $86 \mathrm{ACl}$ & 5 & $253-261$ \\
\hline & $30 I A C G I$ & 5 & $279-287$ \\
\hline & 20IATTI & 8 & $324-346$ \\
\hline
\end{tabular}

note that each of these loci is located at or near the end of a linkage group; the associated supercontigs contain the genetic loci LF347, LF115, and AEGI8, respectively [5]. However, after excluding these three loci, most loci met Hardy-Weinberg (HW) expectations, with the exception of the Port au Prince population where seven of the remaining 17 loci showed significant HW deviations. The observed HW deviations across all populations were due to heterozygote deficits.

Significant population differentiation was observed with 10 of $21(48 \%)$ pairwise $\mathrm{F}_{\mathrm{ST}}$ comparisons (Table 4$)$. The mean pairwise $\mathrm{F}_{\mathrm{ST}}$ across the 20 polymorphic loci ranged from 0.014 (La Poudriere and Grand Goave) to 0.104 (Grand Goave and Barriere-Jeudy). Port au Prince showed significant differentiation with four of the other six populations, while the La Poudriere population showed no differentiation with any of the other populations. To test for isolation by distance, we regressed the pairwise $\mathrm{F}_{\mathrm{ST}} /\left(1-\mathrm{F}_{\mathrm{ST}}\right)$ against the natural logarithm of the distance between sites (Additional File 4). We found no association between them $\left(R^{2}=0.0355, P=0.41\right)$. That is, while distances between sites varied from $\sim 1.4$ to $44.5 \mathrm{~km}$, the observed levels of genetic differentiation between sites were sometimes high and sometimes low irrespective of distance. This result is typical for Ae. aegypti populations as adults generally travel very short distances from breeding sites in a lifetime, often $\sim 100 \mathrm{~m}$ or less, with some evidence for greater but still modest dispersal $(\sim 800 \mathrm{~m})$ [27-31]. Longer range dispersal and population differentiation are more likely to reflect the effects of mosquito transport via human activities than relative distances among breeding sites and active dispersal by individual mosquitoes.

\section{Conclusion}

We demonstrate that the Ae. aegypti genome is well-populated with microsatellite loci suitable for genotyping and outline an efficient strategy for identifying and validating microsatellites from genome supercontig assemblies. While multiple repeat motifs were evident and represented as single copy sequences, tri-nucleotide microsatellites were the most common, and with tetra-nucleotide microsatellites, the most applicable to development as genetic loci. We developed several multiplex-ready PCR groups of microsatellite loci that permit rapid genotyping, and demonstrate their utility with Ae. aegypti population samples from Haiti. We observed high polymorphism with a mean of 8.75 alleles per locus, high allelic polymorphic information content (PIC), and evidence for population differentiation even across relatively short geographic distances as is often reported for Ae. aegypti.

\section{Methods \\ Mosquito strains and populations}

Preliminary screens of microsatellites for single copy number and polymorphism were evaluated among individuals from four Ae. aegypti laboratory colonies, Liverpool-IB12, MOYO-R, Trinidad, and Haiti. The laboratory strains have been maintained as colonies for an unknown number of generations and likely carry reduced polymorphism compared to field-collected individuals. The Liverpool-IB12 strain was the source for the Ae. aegypti genome

Table 4: Pairwise $F_{\mathrm{ST}}$ estimates for populations from Haiti based on 20 microsatellite loci

\begin{tabular}{lllllll}
\hline & La Poudriere & Grand Goave & Bino & Ca-Ira & Barriere-Jeudy & Chawa \\
\hline Port au Prince & 0.051 & $0.042^{*}$ & 0.025 & $0.059^{*}$ & $0.046^{*}$ & $0.026^{*}$ \\
La Poudriere & & 0.014 & 0.039 & 0.092 & 0.097 & 0.086 \\
Grand Goave & & & 0.062 & $0.080^{*}$ & $0.104^{*}$ & $0.077^{*}$ \\
Bino & & & 0.063 & 0.033 & 0.033 \\
Ca-Ira & & & & $0.074^{*}$ & $0.066^{*}$ \\
Barriere-Jeudy & & & & & & $0.047^{*}$ \\
\hline
\end{tabular}

$* \mathrm{P}<0.05$ using Bonferroni adjusted significant thresholds to account for multiple testing. 
project [22], details on the MOYO-R and Trinidad strains are provided elsewhere [32], and the Haiti strain was established from ovitrap samples collected in 2006.

Field samples from Haiti were collected from three localities (Port-au-Prince, Grand Goave, and Leogane) during June, 2008; samples from Leogane were collected at five different regions in the city (Barriere-Jeudy, Bino, Ca-Ira, Chawa, La Poudriere). Port au Prince and Grand Goave were separated by the greatest distance $(\sim 44.5 \mathrm{~km})$. All sites in Leogane were within $\sim 10 \mathrm{~km}$ of each other with La Poudriere and Ca-Ira being the closest $(\sim 1.3 \mathrm{~km})$. At each site, samples included larval collections from containers around households, standard ovitrap collections with 10 traps at each site, or both larval and ovitrap collections. Ovitrap sampling and mosquito rearing were performed generally as reported previously [33]. Genotype data for all individuals obtained at each sample site were pooled for subsequent analysis.

\section{In silico identification of microsatellites in the Aedes aegypti genome assembly}

Bioinformatic analyses targeted the identification and development of useful microsatellite loci at $10 \mathrm{cM}$ intervals across each of the three Ae. aegypti chromosomes. Supercontig assemblies for microsatellite scans were identified by BLASTn analysis against the Ae. aegypti genome (version AaegL1, March 2006) at VectorBase [24] with sequences previously mapped as RFLP, SNP and SSCP genetic markers [5]. Supercontig assemblies containing individual marker loci were then downloaded from VectorBase and screened with the Tandem Repeats Finder (TRF) program using default parameters [23]. The TRF output was manually scanned and, in most cases, tandem repeats with a period size of 2-4 bp and repeat copy number less than 30 were arbitrarily selected for further analysis.

\section{Primer Design}

In preparation for primer design, a 400-600 bp sequence containing a microsatellite of interest was extracted from the supercontig sequence and subjected to BLASTn analysis against the Ae. aegypti genome sequence at VectorBase to verify that the microsatellite flanking sequences were not highly repetitive. PCR primers were designed for those sequences showing minimal repetitive sequence using Primer3 v.4.0 [34], with the amplicon size target set at $150-400 \mathrm{bp}$. Individual primer pairs selected from the Primer3 output were also subjected to BLAST analysis to verify that they represented single copy sequences in the Ae. aegypti genome.

\section{PCR Amplification}

DNA extractions on individual mosquitoes were performed following a rapid, simple alkaline method [35].
DNA was suspended in a final volume of $1600 \mu \mathrm{l}$ containing 0.01 $\mathrm{M} \mathrm{NaOH}$ and $0.018 \mathrm{M}$ Tris- $\mathrm{HCl}$, pH 8.0. Amplification was performed in $25 \mu$ volumes in 96-well PCR plates (Dot Scientific) in a Mastercycler thermocycler (Eppendorf). Each reaction contained $1 \times$ Taq buffer (50 $\mathrm{mM} \mathrm{KCl}, 10 \mathrm{mM}$ Tris $\mathrm{pH}$ 9.0, 0.1\% Triton X), $1.5 \mathrm{mM}$ $\mathrm{MgCl}_{2}, 200 \mu \mathrm{M}$ dNTPs, 5 pmoles of each primer, 1 unit of Taq DNA polymerase, and $1 \mu \mathrm{l}$ of genomic DNA as prepared above. Thermocycling conditions were: 5 minutes at $94^{\circ} \mathrm{C}$, followed by 30 cycles of a 1 minute denaturation at $94^{\circ} \mathrm{C}$, a 1 minute anneal at $60^{\circ} \mathrm{C}$, a 2 minute extension at $72^{\circ} \mathrm{C}$, followed by a 10 minute final extension cycle at $72^{\circ} \mathrm{C}$. PCR products were size fractionated by electrophoresis in $2 \%$ agarose gels stained with ethidium bromide, and visualized under UV light.

\section{Polymorphism Determination and Multiplex PCR}

Microsatellites with single copy amplicons based on agarose gel screens were assayed for allelic polymorphisms on $6 \%$ denaturing polyacrylamide gels using the GenePrint ${ }^{\circledast}$ STR System (Promega). Data for single copy sequences have been submitted to the GenBank STS database (Additional File 5). Select primer pairs for loci that showed polymorphism among strains were evaluated and assembled into multiplex groups of four or five loci per group. Multiplex group criteria included efforts to combine microsatellite loci that provided broad coverage across each chromosome and exhibited detectable amplicon size differences on agarose gels. Multiplex groups were tested for amplification with DNA from single mosquitoes in $25 \mu \mathrm{l}$ PCR reactions as outlined above.

\section{Fragment Analysis and Genotyping}

Flurochrome-labeled forward primers (6-FAM ${ }^{\circledR}, \mathrm{HEX}^{\circledR}$, $\mathrm{NED}^{\circledR}$ ) were synthesized by Integrated DNA Technologies and Applied Biosystems for each primer pair that successfully amplified in the multiplex group. Multiplex PCR products were diluted 1:10 in sterile water and $1 \mu \mathrm{l}$ of this dilution was added to $9 \mu$ l of a mixture of HiDi Formamide $^{\circledast}$ (ABI \#4311320) and ROX 400HD ${ }^{\circledast}$ standard (ABI \#402985) in 96 well PCR plates. The samples were then denatured for 2 minutes at $95^{\circ}$ and immediately placed on ice. Plates were kept covered during processing due to the light-sensitive standard and dye-labeled primers. Genotyping was performed using an ABI 3730 Genetic Analyzer with the GeneMapper ${ }^{\circledast}$ V.4.0 software package.

\section{Population data analysis}

Analysis of genetic diversity among Ae. aegypti populations from Haiti included calculations of the observed and expected heterozygosities and number of alleles per locus. $\mathrm{F}_{\mathrm{IS}}$ (inbreeding coefficient) and $\mathrm{F}_{\mathrm{ST}}$ (fixation index) were estimated following Weir and Cockerham [36] using FSTAT 2.9.3 [37,38]. Deviations from Hardy-Weinberg expectations were determined using FSTAT 2.9.3. Critical 
significance levels were adjusted for multiple comparisons using Bonferroni corrections. Allelic polymorphic information content (PIC) was calculated using the Excel Microsatellite Toolkit 3.3.1 [39]. PIC $=1-\Sigma\left(P_{\mathrm{ij}}\right)^{2}$ where $\mathrm{P}_{\mathrm{ij}}$ is the frequency of the $i$ th allele in the $j$ th population for each locus. Genetic isolation by distance was evaluated by linear regression of the pairwise $\mathrm{F}_{\mathrm{ST}}$ values as $\mathrm{F}_{\mathrm{ST}} /\left(1-\mathrm{F}_{\mathrm{ST}}\right)$ on the natural logarithm transformation of the distance between sites using $\mathrm{R}$ version 2.6.0 [40].

\section{Abbreviations}

TRF: Tandem Repeats Finder; wgs: whole genome sequence; PIC: polymorphic information content; HW: Hardy-Weinberg.

\section{Authors' contributions}

DDL coordinated the project and drafted the manuscript. KOW carried out laboratory assays and data analysis for the Haiti populations. BD assisted with microsatellite characterization and developed the multiplex-ready PCR assays. RRH assisted with microsatellite identification and characterization and data analysis. AM and SRE assisted with microsatellite identification and characterization. BWH assisted with microsatellite analysis. TGS coordinated collection of samples from Haiti. DWS planned and supervised the project and assisted in writing the manuscript. All authors read and approved the final manuscript.

\section{Additional material}

\section{Additional file 1}

Microsatellite variation in lab strains. The data provided include detailed information on all microsatellite sequences screened for copy number and polymorphism against four laboratory strains, and include primer sequences for each locus.

Click here for file

[http://www.biomedcentral.com/content/supplementary/14712164-10-590-S1.DOC]

\section{Additional file 2}

Re-designed PCR primer sequences. The data provided represent the complete descriptions for the previously reported microsatellite loci for which new PCR primers were designed.

Click here for file

[http://www.biomedcentral.com/content/supplementary/14712164-10-590-S2.RTF]

\section{Additional file 3}

Microsatellite polymorphisms among field populations from Haiti. The data provided represent the locus by population statistics that include allele numbers, heterozygocities, Hardy-Weinberg expectations, and allelic polymorphic information content.

Click here for file

[http://www.biomedcentral.com/content/supplementary/14712164-10-590-S3.DOC]

\section{Additional file 4}

Regression analysis of pairwise $F_{S T} /\left(1-F_{S T}\right)$ against pairwise natural logarithm-transformed distances among sample sites in Haiti. The data provided represent the comparison of microsatellite-based population structure to distances between populations in Haiti.

Click here for file

[http://www.biomedcentral.com/content/supplementary/14712164-10-590-S4.DOC]

\section{Additional file 5}

GenBank accession numbers for STS sequences of microsatellite loci. The data provided represent the complete list of single copy microsatellite loci with the associated GenBank Sequence Tagged Site (STS) database accession numbers.

Click here for file

[http://www.biomedcentral.com/content/supplementary/14712164-10-590-S5.DOC]

\section{Acknowledgements}

We thank Tim McCleary for assistance with fragment analysis. We also thank Ronald Rosemond, Guytaud Leriche, and Nicov Elaus for technical assistance with field collections in Haiti. This work was supported by grant ROI-AI059342 from the National Institute of Allergy and Infectious Diseases, National Institutes of Health, Bethesda, USA.

\section{References}

I. Severson DW, Knudson KL, Soares MB, Loftus B]: Aedes aegypti genomics. Insect Biochem Mol Biol 2004, 34:7I 5-72I.

2. Munstermann LE, Craig GB Jr: Genetics of Aedes aegypti: updating the linkage map. J Hered 1979, 70:29I-296.

3. Antolin MF, Bosio CF, Cotton J, Sweeney W, Strand MR, Black WC: Intensive linkage mapping in a wasp (Bracon hebetor) and a mosquito (Aedes aegypti) with single-strand conformation polymorphism analysis of random amplified polymorphic DNA markers. Genetics 1996, 143:1727-1738.

4. Severson DW, Mori A, Zhang Y, Christensen BM: Linkage map for Aedes aegypti using restriction fragment length polymorphisms. J Hered 84:24I-247.

5. Severson DW, Meece JK, Lovin DD, Saha G, Morlais I: Linkage map organization of expressed sequence tags and sequence tagged sites in the mosquito, Aedes aegypti. Insect Mol Biol 2002, I I:37I-378.

6. Fulton RE, Salasek ML, DuTeau NM, Black WC: SSCP analysis of cDNA markers provides a dense linkage map of the Aedes aegypti genome. Genetics 200I, 1 58:715-726.

7. Severson DW, Mori A, Zhang Y, Christensen BM: The suitability of restriction fragment length polymorphism markers for evaluating genetic diversity among and synteny between mosquito species. Am J Trop Med Hyg 1994, 50:425-432.

8. Severson DW, Mori A, Kassner VA, Christensen BM: Comparative linkage maps for the mosquitoes, Aedes albopictus and Aedes aegypti, based on common RFLP loci. Insect Mol Biol 1995, 4:4I-45.

9. Ferdig MT, Taft AS, Severson DW, Christensen BM: Development of a comparative genetic linkage map for Armigeres subalbatus using Aedes aegypti RFLP markers. Genome Res 1998, 8:4|-47.

10. Mori A, Severson DW, Christensen BM: Comparative linkage maps for the mosquitoes, Culex pipiens and Aedes aegypti, based on common RFLP loci. J Hered 1999, 90:160-164.

II. Mori A, Tomita T, Hidoh O, Kono Y, Severson DW: Comparative map development and identification of an autosomal locus for insensitive acetylcholinesterase-mediated insecticide resistance in Culex tritaeniorhynchus. Insect Mol Biol 200I, 10:197-203. 
12. Anderson JR, Grimstad PR, Severson DW: Chromosomal evolution among six mosquito species (Diptera: Culicidae) based on shared restriction fragment length polymorphisms. Mol Phylogenet Evol 200I, 20:316-32I.

13. Tautz D, Renz M: Simple sequences are ubiquitous repetitive components of eukaryotic genomes. Nucleic Acids Res 1984 | 2:4|27-4|37.

14. Tautz D: Hypervariability of simple sequences as a general source for polymorphic DNA markers. Nucleic Acids Res 1989. | 7:6463-647|.

15. Zane L, Bargelloni L, Patarnello T: Strategies for microsatellite isolation: a review. Mol Ecol 2002, II:I-16.

16. Huber K, Mousson L, Rodhain F, Failloux A-B: Microsatellite sequences as markers for population genetic studies of the mosquito Aedes aegypti. Am J Trop Med Hyg 1999, 6 I: I00 I- 1003.

17. Fagerberg AJ, Rulton RE, Black WC: Microsatellite loci are not abundant in all arthropod genomes: analyses in the hard tick, Ixodes scapularis and the yellow fever mosquito, Aedes aegypti. Insect Mol Biol 200I, 10:225-236.

18. Chambers EW, Meece JK, McGowan JA, Lovin DD, Hemme RR, Chadee DD, McAbee K, Brown SE, Knudson KL, Severson DW: Microsatellite isolation and linkage group identification in the yellow fever mosquito Aedes aegypti. J Hered 2007, 98:202-210.

19. Ravel S, Herve J-P, Diarrassouba S, Kone A, Cuny G: Microsatellite markers for population genetic studies in Aedes aegypti (Diptera: Culicidae) from Cote d'Ivoire: evidence for a microgeographic genetic differentiation of mosquitoes from Bouake. Acta Trop 2002, 82:39-49.

20. Huber K, Mousson L, Rodhain F, Failloux A-B: Isolation and variability of polymorphic microsatellite loci in Aedes aegypti, the vector of dengue viruses. Mol Ecol Notes 200I, I:219-222.

21. Slotman MA, Kelly NB, Harrington C, Kitthawee S, Jones W, Scott TW, Cacoone A, Powell JR: Polymorphic microsatellite markers for studies of Aedes aegypti (Diptera: Culicidae), the vector of dengue and yellow fever. Mol Ecol Notes 2007, 7:168-17I.

22. Nene V, Wortman JR, Lawson D, Haas B, Kodira C, Tu Z, Loftus B, Xi Z, Megy K, Grabherr M, Ren Q, Zdobnov EM, Lobo NF, Campbell KS, Brown SE, Bonaldo MF, Zhu J, Sinkins S, Hogenkamp DG, Amedo $\mathrm{P}$, Arensburger P, Atkinson PW, Bidwell S, Biedler J, Birney E, Bruggner RV, Costas J, Coy MR, Crabtree J, Crawford M, deBruyn B, DeC aprio D, Eiglmeier K, Eisenstadt E, El-Dorry H, Gelbart WM, Gomes SL, Hammond M, Hannick LI, Hogan JR, Holmes MH, Jaffe D, Johnston SJ, Kennedy R, Koo H, Kravitz S, Kriventseva EV, Kulp D, LaButti K, Lee E, Li S, Lovin DD, Mao C, Mauceli E, Menck CFM, Miller JR, Montgomery P, Mori A, Nascimento AL, Naveira HF, Nusbaum C, O'Leary S, Orvis J, Pertea M, Quesneville H, Reidenbach KR, Rogers Y-H, Roth CW, Schneider JR, Schatz M, Shumway M, Stanke M, Stinson EO, Tubio JMC, VanZee JP, Verjovski-Almeida S, Werner D, White O, Wyder S, Zeng Q, Zhao Q, Zhao Y, Hill CA, Raikhel AS, Soares MB, Knudson DL, Lee NH, Galagan J, Salzberg SL, Paulsen IT, Dimopoulos G, Collins FH, Birren B, Fraser-Liggett CM, Severson DW: Genome sequence of Aedes aegypti, a major arbovirus vector. Science 2007, 316:1718-1722.

23. Benson G: Tandem repeats finder: a program to analyze DNA sequences. Nucleic Acids Res 1999, 27:573-580.

24. VectorBase: A. aegypti 2008 [http://aaegypti.vectorbase.org/ index.php].

25. Hayden MJ, Nguyen TM, Waterman A, Chalmers KJ: Multiplexready PCR: a new method for multiplexed SSR and SNP genotyping. BMC Genomics 2008, 9:80.

26. Huber K, Le Loan L, Hoang TH, Ravel S, Rodhain F, Failloux A.-B Genetic differentiation of the dengue vector, Aedes aegypti (Ho Chi Minh City, Vietnam) using microsatellite markers. Mol Ecol 2002, I I:1629-1635.

27. McDonald PT: Population characteristics of domestic Aedes aegypti (Diptera: Culicidae) in villages on the Kenya coast. II. Dispersal within and between villages. I Med Entomol 1977, I 4:49-53.

28. Trpis $M$, Hausermann $W$ : Dispersal and other population parameters of Aedes aegypti in an African village and their possible significance in epidemiology of vector-borne disease. Am J Trop Med Hyg 1986, 35: 1263-I279.

29. Reiter P, Amador MA, Anderson RA, Clark GG: Dispersal of Aedes aegypti in an urban area after blood-feeding as demonstrated by rubidium-marked eggs. Am J Trop Med Hyg 1995, 52: I 77- I79.
30. Colton YM, Chadee DD, Severson DW: Natural skip oviposition of the mosquito Aedes aegypti indicated by codominant genetic markers. Med Vet Entomol 2003, 17:195-204.

31. Harrington LC, Scott TW, Lerdthusnee K, Coleman RC, Costero A Clark GG, Jones JJ, Kitthawee S, Kittayapong P, Sithiprisasna R, Edman JD: Dispersal of the dengue vector Aedes aegypti within and between rural communities. Am J Trop Med Hyg 2005, 72:209-220

32. Schneider JR, Mori A, Romero-Severson J, Chadee DD, Severson DW: Investigations of dengue-2 susceptibility and body size among Aedes aegypti populations. Med Vet Entomol 2007, 21:370-376.

33. Cha S-J, Chadee DD, Severson DW: Population dynamics of an endogenous meiotic drive system in Aedes aegypti in Trinidad. Am J Trop Med Hyg 2006, 75:70-77.

34. Primer3 2007 [http://frodo.wi.mit.edu/].

35. Rudbeck L, Dissing J: Rapid, simple alkaline extraction of human genomic DNA from whole blood, buccal epithelial cells, semen and forensic stains for PCR. Biotechniques 1998, 25:588-592.

36. Weir BS, Cockerham CC: Estimating F-statistics for the analysis of population structure. Evolution 1984, 38: I358-1370.

37. Goudet J: FSTAT (Version I.2): a computer program to calculate F-statistics. J Hered 1995, 86:485-486.

38. FSTAT 2.9.3 2002 [http://www2.unil.ch/popgen/softwares/ fstat.htm].

39. Excel Microsatellite Toolkit 3.3.1 2008 [http://www.animalge nomics.ucd.ie/sdepark/ms-toolkit/].

40. R version 2.6.0 2009 [http://www.r-project.org/].
Publish with Biomed Central and every scientist can read your work free of charge

"BioMed Central will be the most significant development for disseminating the results of biomedical research in our lifetime. "

Sir Paul Nurse, Cancer Research UK

Your research papers will be:

- available free of charge to the entire biomedical community

- peer reviewed and published immediately upon acceptance

- cited in PubMed and archived on PubMed Central

- yours - you keep the copyright
Biolmedcentral 